\title{
PENGARUH PENGGUNAAN KRIKIL MANTUP SEBAGAI BAHAN PERKERASAN JALAN (AC-WC)
}

\author{
Sugeng Dwi Hartantyo ${ }^{1}$; Beni Hermanto ${ }^{2}$ \\ ${ }^{1,2}$ Fakultas Teknik Universitas Islam Lamongan \\ e-mail: sugeng.dwih@gmail.com ; beniherman22@gmail.com ;
}

\begin{abstract}
This research aims to find out how the process of making hot asphalt mixtures (AC-WC) using grated mantup as a substitute for coarse aggression, and aims to find out how the influence of using grated mantras as hot asphalt mixture $(A C-W C)$. This research method used is the exprimental trial and error method of Marshall testing methodology to analyze the properties of percent cavity in the mixture (VIM), percent cavity filled with asphalt (VFB), percent cavity between mineral aggregate (VMA), stability (Stability), melt (Flow) and Marshall Quatient. The substitution of cricile variation is $0 \%, 25 \%, 50 \%$, $100 \%$ of the coarse aggregate weight in this study indicating that the most ideal Marshall Properties value is calculated using the regression model equation with the highest index of determination where the index value of determination is obtained $(R 2)=1$ for Marshall properties which is the highest is the substitution of gravel mantup 100\% with Marshall parameters which includes: Stability $979.03 \mathrm{~kg}$, VIM 97.71\%, VMA 18.68\%, VFWA 78.21\%, Flow $3.13 \mathrm{~mm}$, Marshall Question 316.46\%. From these results the substitution of gravel Mantup with a level of $100 \%$ meets the criteria in Indonesian national standards.
\end{abstract}

Keywords: Mantup Gravel, Manufacture, Hot Asphalt (AC-WC)

\begin{abstract}
ABSTRAK
Penelitian ini bertujuan untuk mengetahui bagaimana proses pembuatan campuran aspal panas (AC$W C$ ) dengan menggunakan parutan mantup sebagai pengganti agresi kasar, dan bertujuan untuk mengetahui bagaimana pengaruh penggunaan parutan sebagai campuran aspal panas (AC-WC) . Metode penelitian yang digunakan adalah metode exprimental trial and error metodologi pengujian Marshall untuk menganalisis sifat persen rongga dalam campuran (VIM), persen rongga diisi dengan aspal (VFB), persen rongga antara agregat mineral (VMA), stabilitas (Stabilitas)), melt (Flow) dan Marshall Quatient. Substitusi variasi cricile adalah 0\%, 25\%, 50\%, 100\% dari berat agregat kasar dalam penelitian ini menunjukkan bahwa nilai Marshall Properties paling ideal dihitung menggunakan persamaan model regresi dengan indeks penentuan tertinggi di mana nilai indeks penentuan diperoleh $(R 2)=1$ untuk sifat Marshall yang tertinggi adalah substitusi dari kerikil mantup 100\% dengan parameter Marshall yang meliputi: Stabilitas 979,03 kg, VIM 97,71\%, VMA 18,68\%, VFWA 78,21\%, Aliran 3,13 mm, Marshall Pertanyaan 316,46\%. Dari hasil ini substitusi kerikil Mantup dengan tingkat $100 \%$ memenuhi kriteria dalam standar nasional Indonesia.
\end{abstract}

Kata Kunci: Gravel Mantup, Pembuatan, Hot Asphalt (AC-WC)

\section{PENDAHULUAN}

\subsection{Landasan Teori}

Jalan adalah suatu prasarana perhubungan darat dalam bentuk apapun, meliputi segala bagian jalan termasuk bangunan pelengkap dan perlengkapannya yang di peruntukan bagi lalu lintas (Menurut undang - undang jalan raya no. 13 /1980). Panjang jalan di rinci menurut jenis permukaannya pada tahun 1987 untuk jalan aspal sepanjang $93.778 \mathrm{~km}$, jalan bukan aspal $120.998 \mathrm{~km}$, sehingga total panjang jalan aspal sepanjang $214.776 \mathrm{~km}$. sedangkan pada tahun 2012 untuk jalan aspal panjangnya $285.252 \mathrm{~km}$, jala bukan aspal sepanjang $216.717 \mathrm{~km}$, 
sehingga total panjang jalan tahun 2012 mencapai $501.969 \mathrm{~km}$ (kementrian pekerjaan umum dan dinas pekerjaan umum). Pertumbuhan jalan dari tahun 1987 hingga 2012 mencapai $150 \%$.

Ketidak tersediaan bahan pembentuk aspal sering sekali menjadi kendala dalam pelaksanaan pembangunan (Zaenuri, Romadhon, Gunarto, \& Cahyono, 2018) (Vitasmoro, Chandra, \& Jatmiko, 2019). berdasarkan permasalahan tersebut maka perlu dicari langkahlangkah penyelesaian yang dapat diambil dengan menggunakan potensi sumber daya alam yang tersedia sekitar lokasi proyek pembangunan (April Gunarto, 2019). Mantup merupakan sebuah kecamatan yang ada diwilayah kabupaten lamongan. Kecamatan Mantup terletak 20-23 km sebelah selatan Kota kabupaten Lamongan, yang berbatasan dengan wilaya kabupaten Mojokerto dan Kabupaten Gersik. Memiliki luas wilayah datara tinggi 9.307,285 Hektar Denga tata guna tanah: -tanah pertanian: 5.952,60 hektar -tanah hutan 2.306 hektar. Jumlah penduduk Kecamatan Mantup sejumlah 41.223 jiwa. Di wilayah ini menyimpan kekayaan alam berubah batuan kerikil.

Sedangkan potensi batu yang berada pada wilayah kecamatan mantup termasuk dalam jenis batuan beku. Ada tiga tipe batuan beku menurut posisi pembekuannya yaitu plutonik, gang, dan lelehan. Batuan beku plutonik membeku didalam dapur magma,sedangkan batuan beku gang/korok membeku dicelah-celah antar lapisan kulit bumi. Dan batuan lelehan/ekstrusif membeku di luar kulit bumi. Conton-contoh batuan yang termasuk batuan beku meliputi granit, peridotit, gabro, profir, apung, dan obsidian.

Krikil yang berasal dari datara tinggi yang berada didaerah mantup adalah krikil sebagai hasil disintegrasi alami dari batuan atau batu pecah yang diperoleh dari industri pemecah batu dan memounyai ukuran butiran yang bervariasai. Batuan krikil ini memiliki tingkat kekerasan yang berbeda dengan batuan kali atau split yang biasa digunakan pada umumnya.

Menurut perkerasaan jalan di bagi menjadi 3 yaitu perkerasaan lentur, perkerasaan kaku dan perkerasan komposit. Perkerasaan lentur semakin berkembang dengan di buatnya perkerasan aspal beton campuran panas. Laton memiliki tiga pembagian lapisan yaitu lapisan pondasi ( AC - Base), Lapis Antara (AC-BC), dan Lapis permukaan (AC-WC) (Departemen Pemukiman dan Pengembangan Wilayah, 2013).

Dalam penelitian terdahulu menggunakan metodologi pengujian marshall untuk menganalisa sifat-sifat dari persen rongga dalam campuran (VIM), persen rongga terisi aspal (VFB), persen rongga diantara mineral agregat (VMA), stabilitas (Stability), kelelehan (Flow) dan Marshall Quatient. Pembuatan benda uji sebanyak 6 buah, 3 benda uji untuk campuran aspal yang menggunakan batu putih dan 3 benda uji untuk campuran aspal yang menggunakan batu hitam (batu kali/batu gunung) dengan kadar aspal 5,5\%. Penelitian ini dilakukan di laboratorium Teknik Sipil Universitas Tribhuwana Tunggadewi, Malang. Tahapan pelaksanaan 
meliputi pemeriksaan aspal AC 60/70, pemeriksaan agregat kasar (batu hitam dan batu putih), pemeriksaan agregat halus (batu hitam dan batu putih), pemeriksaan filler, pembuatan benda uji dan pengujian Marshall. (Ngita, Paskalis 2013)

\subsection{Tujuan Penelitihan}

Untuk mengetahui proses pembuatan campuran aspal panas (AC-WC) dengan menggunkan kerikil mantup sebagai bahan pengganti agregat kasar

Untuk mengetahui pengaruh campuran kerikil mantup terhadap aspal panas (AC-WC).

\section{METODE PENELITIAN}

\subsection{Tempat dan Waktu Pelaksanaan}

Pelaksanaan penelitian seperti pembuatan benda uji, perawatan dan pengujian benda uji di lakukan di laboratorium program studi Teknik Sipil Fakultas Teknuk Universitas Islam Lamongan. Penelitian yang di uji pada Asphalt Concrete Wearing Course (AC-WC) adalah Marshall test dengan pergantian sebagian filler berupa kombinasi dari kerikil mantup. Semua bahan yang di gunakan pada penelitian ini mengacu pada spesifikasi umum yang di keluarkan.

Dalam penelitian ini metode penelitian yang di gunakan adalah Trial and Error dengan uji laboratorium. Dengan jenis pengujian sebagai berikut :

1. Uji bahan penyusun Aspal

a. Uji kualitas Aspal

b. Uji kualitas Agregat halus

c. Uji kualitas Agregat kasar

d. Uji Filler

2. Uji Batu Kapur sebagai agregat halus

Alat yang di gunakan untuk mengumpulkan data atau fasilitas yang digunakan peneliti dalam mengumpulkan material yaitu Batu Kapur Mantup Lamongan, Agregat kasar, Agregat halus, Aspal, Filler.

\subsection{Teknik pengumpulan data}

Alat yang di gunakan untuk mengumpulkan data atau fasilitas yang di gunakan peneliti dalam mengumpulkan material yaitu krikil mantup, Agregat kasar, Agregat halus, Aspal, Filler.

\subsection{Data Primer}

Data primer adalah sumber data yang diperoleh peneliti secara langsung.

\subsection{Data Sekunder}

Data sekunder adalah data yang diperoleh peneliti secara tidak langsung. 


\subsection{Identifikasi Variabel}

Tahap identifikasi variable dalam hal ini di ambil sampel penelitian dan dokumentasi saat penelitian berlangsung selama di laboratorium, karena dalam tahap ini penelitian di lakukan agar data yang di peroleh kongkret.

\section{PEMBAHASAN}

\subsection{Stabilitas (Stability)}

Stabilitas adalah kemampuan maksimal suatu benda uji campuran beton aspal menahan beban sampai terjadi kelelehan plastis.Nilai stabilitas diperoleh dari persamaan :

$\mathrm{S}=\mathrm{p} \times \mathrm{g}$

Keterangan :

$\mathrm{S}=$ Angka stabilitas sesungguhnya

$\mathrm{p}=$ Pembacaan arloji stabilitas $\mathrm{x}$ kalibrasi alat

$\mathrm{q}=$ Angka koreksi benda uji

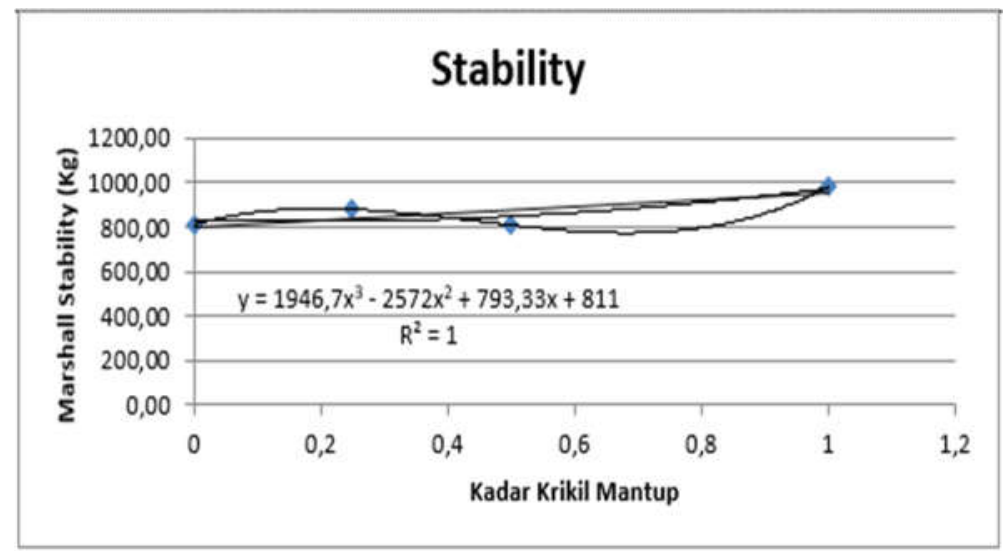

Gambar 1: gambar nilai stabilitas

\subsection{Void in Mix (VIM)}

Rongga udara dalam campuran (VIM) dalam campuran perkerasan beraspal terdiri atas ruang udara diantara partikel agregat yang terselimuti aspal. Volume rongga udara dalam campuran dapat ditentukan dengan rumus berikut:

$$
V I M=100-\frac{100 x \text { berat volume } \mathrm{b} . \mathrm{u}}{\mathrm{B} . \mathrm{J} \text { maksimum teoritis }}
$$

Berat jenis maksimum teoritis :

$$
V I M=100 \% \frac{100}{\frac{\% \text { Agregat }}{\text { B.JAgregat }}+\frac{\% \text { Aspal }}{\text { B.JAspal }}}
$$




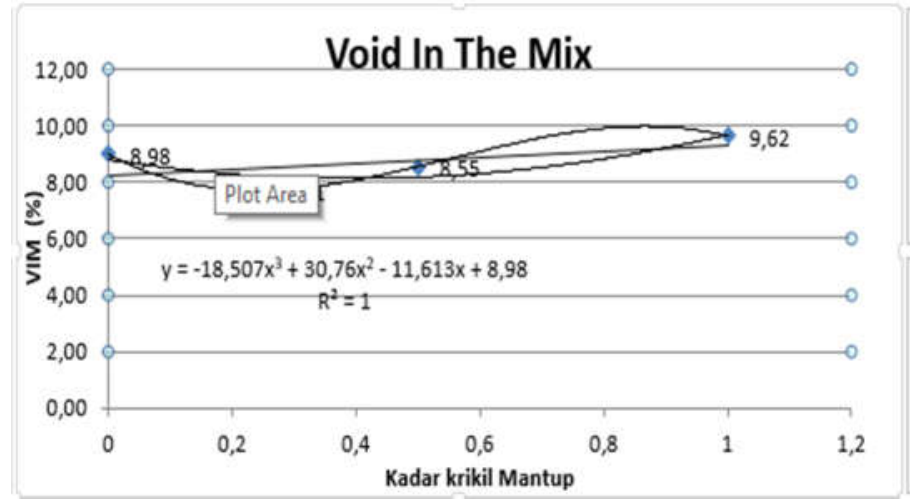

Gambar 2: gambar nilai VIM

\subsection{Void in Mineral Aggregates (VMA)}

Rongga antar mineral agregat (VMA) adalah ruang rongga diantara partikel agregat pada suatu perkerasan, termasuk rongga udara dan volume aspal efektif (tidak termasuk volume aspal yang diserap agregat). VMA dapat dihitung dengan rumus berikut :

$$
V M A=100-\frac{(100-\% \text { Aspal }) \times \text { berat volume b. u }}{\text { B. J Agregat }}
$$

Keterangan :

VMA : Rongga udara pada mineral agregat (\%)

\%Aspal : Kadar aspal terhadap campuran (\%)

B.J. Agregat : Berat jenis efektif

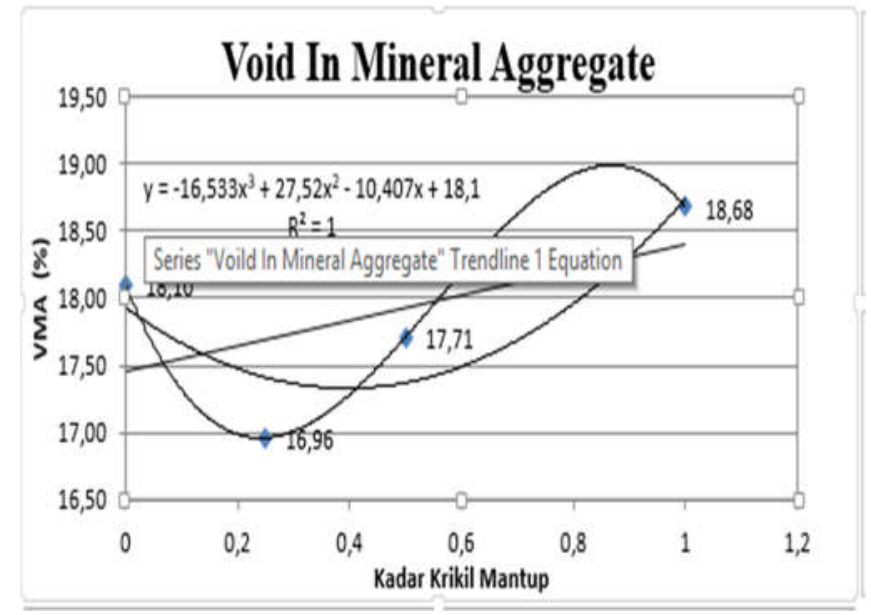

Gambar 3: gambar nilai VMA

\subsection{Voids Filled With Asphalt (VFWA)}


Rongga terisi aspal atau Void Filled with Asphalt (VFWA) adalah persen rongga yang terdapat diantara partikel agregat (VMA) yang terisi oleh aspal, tidak termasuk aspal yang diserap oleh agregat. Rumus adalah sebagai berikut:

$V F W A=100 \times \frac{(\mathrm{VMA}-\mathrm{VIM})}{\mathrm{VMA}}$

Keterangan :

VFWA : Rongga udara terisi aspal (\%)

VMA : Rongga udara pada mineral agregat (\%)

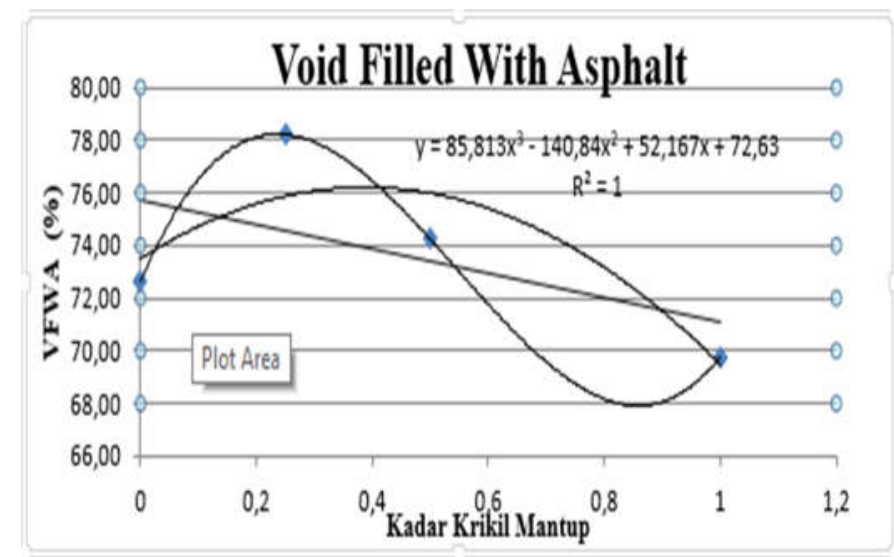

VIM : Rongga udara pada campuran setelah pemadatan (\%)

\section{Gambar 4: gambar nilai VFA}

\subsection{Kelelehan (Flow)}

Nilai flow ditunjukkan oleh jarum arloji pembacaan flow pada alat Marshall. Untuk arloji pembacaan flow, nilai yang didapat sudah dalam satuan $\mathrm{mm}$, sehingga tidak perlu dikonversi lebih lanjut.

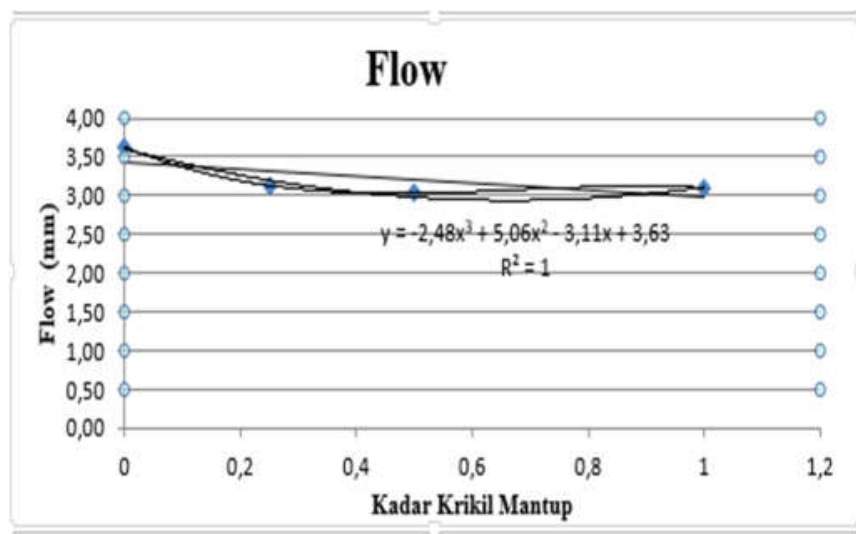

Gambar 5: gambar nilai Flow

\subsection{Marshall Qoutient (MQ)}


Marshall Quotient adalah perbandingan antara nilai stabilitas denganflow. Marshall Quotient merupakan indikator dalam menentukan nilai fleksibitas kelenturan terhadap keretakan.Nilai MQ diperolehdengan persamaan sebagai berikut :

$$
M Q=\frac{M S}{M F}
$$

Keterangan :

$\mathrm{MQ}=$ Marshall Qoutient, $(\mathrm{Kg} / \mathrm{mm})$

MS = Marshall stability, $(\mathrm{Kg})$

$\mathrm{MF}=$ Flow Marshall, $(\mathrm{mm})$

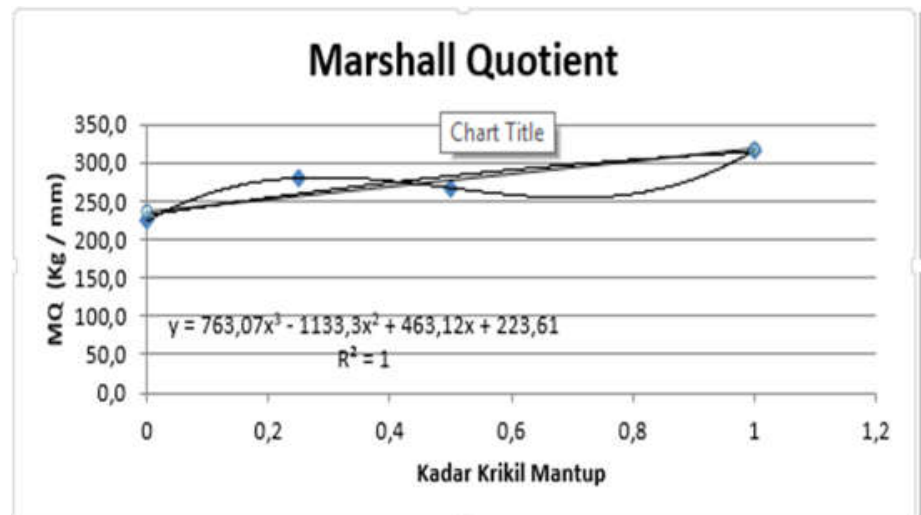

Gambar 6: gambar nilai MQ

Tinjauan Pengantian Krikil Mantup Terhadap Stabilitas Marshall (Marshall Stability)

Pengantian krikil mantup dengan variasi $0 \%, 25 \%, 50 \%, 100 \%$ dari berat Agregat kasar pada campuran, secara umum memperlihatkan kenaikan nilai stabilitas seiring dengan kenaikan prasentase pengantian agregat kasar dengan krikil mantup. Nilai stabilitas tertinggi mencapai $979 \mathrm{Kg}$ pada pengantian Krikil Mantup sebesar $100 \%$. Hal ini berarti stabilitas mengalami kenaikan ketika menggunakan Krikil mantup.

Tinjauan Subtitusi Krikil Mantup Terhadap Rongga Dalam Agregat (Void In Mineral Aggregate / VMA )

Subtitusi krikil mantup menjadikan nilai void in mineral aggregate mengalami kenaikan dan penurunan Hal ini disebabkan karena agregat krikil mantup dapat mengisi rongga dalam campuran dengan baik pada campuran 100\% agregat kasar.

Tinjauan Subtitusi Krikil Mantup Terhadap Rongga Terisi Aspal (Void Filled With Asphalt / VFWA )

Void filled with asphalt / VFWA merupakan rongga terisi aspal dalam campuran setelah mengalami pemadatan yang dinyatakan dalam persen setelah mengalami pemadatan terhadap 
void in mineral aggregate / VMA. Subtitusi krikil mantup menjadikan nilai void filled with asphalt mengalami penurunan dan kenaikan dalam variasi krikil mantup. Hal ini disebabkan karena perbedaan agregat yang tercampur dengan aspal. Nilai void filled with asphalt tertinggi terjadi pada subtitusi krikil mantup 25\% sebesar $78.21 \%$.

\section{Tinjauan Subtitusi Krikil Mantup Terhadap Kelelehan Plastis (Flow)}

Subtituisi krikil mantup membuat nilai flow secara umum mengalami penurunan dan kenaikan pada variasi $100 \%$. Flow mengalami penurunan jika dibandingkan dengan nilai flow pada kadar agregat kasar optimum tetapi mengalami kenaikan ketika kadar krikilmantup 0\%. Nilai Flow tertinggi diperoleh pada penambahan sebesar $25 \%$ yakni sebesar 3,13 $\mathrm{mm}$.

\section{Tinjauan Subtitusi Krikil Mantup Terhadap Marshall Quotient}

Marshall Quotient merupakan hasil bagi marshall dengan flow. Nilai flow menggambarkan nilai fleksibilitas dari campuran. Semakin besar nilai Marshall Quotient menunjukkan bahwa campuran semakin kaku dan sebaliknya semakin kecil Marshall Quotient maka campuran semakin lentur. Faktor yang mempengaruhi Marshall Quotient yaitu nilai stabilitas dan flow. Subtitusi krikil mantup pada kadar agregat kasar terhadap Marshall Quotient secara umum menunjukan kenaikan seiring dengan bertambahnya kadar krikil mantup dalam campuran. Marshall Quotient tertinggi terjadi pada subtitusi krikil mantup $100 \%$

\section{KESIMPULAN dan SARAN}

Berdasarkan penelitian yang telah dilakukan tentang pengaruh penggunaan krikil mantup sebagai bahan pengganti agregat kasar pada campuran Laston type V SNI 03 - 1737 - 1989 dapat disimpulkan sebagai berikut :

Setelah melalui proses pengolahan yang benar Krikil Mantup sampai menjadi agregat kasar, krikil mantup dapat digunakan sebagai bahan tambah campuran aspal panas campuran Laston Tipe V SNI 03-1737-1989.

Subtitusi variasi krikil mantup $0 \%, 25 \%, 50 \%, 100 \%$ dari berat agregat kasar pada penelitian ini menunjukkan nilai Marshall Properties yang paling ideal dihitung dengan menggunakan persamaan model regresi dengan indeks determinasi paling tinggi dimana pada persamaan model tersebut didapatkan nilai indeks determinasi $\left(\mathrm{R}^{2}\right)=1$ untuk Marshall properties yang paling tinggi adalah subtitusi krikil mantup 100\% dengan parameter marshall yang meliputi : Stability 979,03kg, VIM 97,71\%, VMA 18,68\%, VFWA 78,21\%, Flow 3,13 mm, Marshall Question 316,46\%. Dari hasil tersebut subtitusi Krikil Mantup dengan kadar 100\% memenuhi kriteria dalam standar nasional indonesia. 


\section{REFRENSI}

[1] Abdullah, Dan Kartikasari, D 2018. Efluasi Kuat desak Beton Mutu K200 Dengan Menggunakan Agregat Kasar Dari Kecamatan Mantup Dan Penambahan Serat Alam Enceng Gondok. Jurusan Teknik Sipil Universitas Lamongan.

[2] Adyti E. Sutrisno, Kartikasari, D 2017 Pengaruh Penambahan Abu Jerami Padi $\quad$ Padi Terhadap Kuat Tekan Beton, Jurnal Civilla Vol 2 No 2 September 2017 ISSN No. 2503 - 2399, Program Studi Teknik Sipil Fakultas Teknik Universitas Islam Lamongan

[3] Ahmad, Revi.2015. Efek Pemakaian Pasir Laut Sebagai Agregat Halus Padacampuran Aspal Panas (Ac-Bc) Dengan Pengujian Marshall (Jurnal). Jurusan Teknik Sipil dan Perencanaan. Institut Teknologi padan, Padang

[4]Anonim.2017.Modul Perencanaan Mix Design (Perencanaan Campuran Beraspal).Laboratorium Rekayasa Jalan.Departemen Teknik Sipil Universitas islam Lamongan. Lamongan

[5] April Gunarto, A. I. C. K. (2019). Penelitian Campuran Aspal Beton Dengan Menggunakan Filler Bunga Pinus. UKaRsT, 3(1), 37.

https://doi.org/10.30737/ukarst.v3i1.351

[6] Bina Marga, 2002.Perencanaan Campuran Lapis Aspal Beton.Jakarta : Direktorat Jendral Bina Marga

[7] Bina Marga, 2010. Spesifikasi Umum 2010 Divisi 6 Revisi 3 seksi 6 perkerasan Beraspal.Jakarta : Direktorat Jendral Bina Marga

[8] Bina Marga, 2010. Spesifikasi Umum 2010 Revisi 2.Jakarta : Direktorat Jendral Bina Marga

[9] Departemen Pekerjaan Umum, Direktorat Jendral Bina Marga, 1983. Petunjuk Pelaksanaan Lapis Beton Aspal (Laston) No. 13/Pt/B/1983.Jakarta

[10] Departemen Pekerjaan Umum, 1987.Petunjuk Perencanaan Tebal Perkerasaan Lentur Jalan Raya Dengan Metode Analisis Komponen,SKBI-2.3.26.1987.Jakrta:Balai Penerbit Pekerjaan Umum

[11] Dita Kurmadihata 2019. Fleksibilitas Campuran AC-WC Dengan Bahan Tambah Kapur Dan Belerang.

[12] Hartantyo S,D dan Permata, Intan.2018 Pemanfaatan Serat Eceng Gondok Sebagai Campuran Dalam Laston Tipe Vi Sni 03-1737-1989 Di Tinjau Terhadap Marshall Properties. Jurusan Teknik Sipil Universitas Lamongan.Lamongan

[13] Kurniawan 2013. Pemanfaatan Limbah Kramik Sebagai Agregat Kasar Dalam Adukan Beton, Jurnal Matrial Dan Bahan Jakarta Universitan Tri Sakti

[14] Laksita Anggraeni 2013. Ktristik Penggunaan Batu Kapur Puger Sebagai Agregat Kasar Pada Campuran AC-BC

[15] LianaSari Agelina Eva 2013. Potensi Batu Bauksit Pulau Bintan Sebagai Pengganti Agregat Kasar Pada Beton. Jurnal Teknik Sipil Vol 12 No 3 Universitas Atma Jaya, Yogjakarta

[16] Lucky Budiman, Silvia Sukirman 2018. Penggunaan Batu Kapur Batu Kali Cupang Sebagai Subtitusi Agregat Halus Beton Aspal Jenis AC-BC

[17] Shell Bitumen,1990.Shell Bitumen Handbook.

[18] Shodiq, Muhammad, 2018. Alternatif Serat Eceng Gondok Sebagai Bahan Tambahan Pada Campuran Laston Tipe VII Sni 03-1737-1989 Untuk Meningkatkan Kinerja Campuran.Jurusan Teknik Sipil Universitas Lamongan.Lamongan

[19] SNI 03-1737-1989.Tata Cara Pelaksanaan Lapis ASPALl BETON (LASTON) UNTUK JALAN RAYA.Jakarta:BSN.

[20] SNI 06-2489-1991.Metode Pengujian Campuran ASPAL DENGAN ALAT MARSHALL.JAKARTA:BSN.

[21] Standar Nasional Indonesia, 1990. Metode Pengujian Berat Jenis Dan Penyerapan Agregat Kasar, SNI 03-1969-2008.Indonesia : Departemen Pekerjaan Umum.

[22] Standar Nasional Indonesia, 1990. Metode Pengujian Berat Jenis Dan Penyerapan Agregat Halus, SNI 03-1970-2008.Indonesia : Departemen Pekerjaan Umum. 
[23] Standar Nasional Indonesia, 1991. Metode Pengujian Berat Jenis Aspal Padat, SNI 062441-1991.Indonesia : Departemen Pekerjaan Umum.

[24] Standar Nasional Indonesia, 1991. Metode Pengujian Penetrasi Bahan - Bahan Bitumen, SNI 06-2456-1991.Indonesia : Departemen Pekerjaan Umum. .

[25] Standar Nasional Indonesia, 1991. Metode Pengujian Titik Lembek Aspal Dan Ter, SNI 0624534-1991.Indonesia : Departemen Pekerjaan Umum.

[26] Standar Nasional Indonesia, 2008. Metode Pengujian Titik Nyala dan Titik Bakardengan Clave Land, SNI 06-2433-1991.Indonesia : Departemen Pekerjaan Umum.

[27] Sukirman, S., 1992. Perkerasaan Lentur Jalan Raya.Bandung

[28] Sukirman, S., 1993. Perkerasaan Lentur Jalan Raya.Bandung

[29] Sukirman, S., 1995. Perkerasaan Lentur Jalan Raya.Bandung

[30] Sukirman, S., 2003. Beton Aspal Campuran Panas.Bandung

[31] Sunarto, dan Affandy, N,A 2018. Efaluasi Kuat Desak Beton Non Struktural Dengan Menggunakan Fariasi Agregat Kasar mantup dengan Penambahan Serat Alam Enceng Gondok. Jurusan Teknik Sipil Universitas Lamongan.Lamongan

[32] Sudarso, I Dan Hepiyanto, R 2018. Kajian Bahan Tambah Alternatif Serat Enceng Gondok Terhadap Campuran Latasir Sandsheet. Kelas A spesifikasi seksi-6 2010 Bima Marga. Jurusan Teknik Sipil Universitas Lamongan.

[33] Vitasmoro, P., Chandra, A. I., \& Jatmiko, J. (2019). Improving Student 's English Vocabulary Mastery through Animation Cartoon. 363(Icss), 505-509.

[34] Wedyorini Windi Astuti 2015. Pengaruh Bahan Tambah Kapur Terhadap Karakteristk RAP.

[35] Wihardi, Tjangreo M, dkk 2016 Pecahan Marmer Sebagai Pengganti Fersial Agregat Kasar. Jurnal Desain Kontruksi Vol 5 No 1 Universitas Hasanudin Makasar.

[36] Zaenuri, M., Romadhon, R., Gunarto, A., \& Cahyono, A. (2018). PENELITIAN PENGGUNAAN BATU GAMPING SEBAGAI AGREGAT KASAR DAN FILLER PADA ASPAL CAMPURAN AC-BC. UKaRsT, 2(1), 24-35.

[37] Zuraidah, Rahman 2007. Pengaruh Penggunaan Limbah Pecahan Batu Marmer Sebagai Alternatif Agregat Kasar Pada Kekuatan Beton, Universitas Dr. Soetomo Surabaya 